\title{
Towards a Multidisciplinary Research Framework for studying the Digital Transformation of Industry
}

\author{
E. Dessers, S. Dhondt, M. Ramioul. \\ J. De Schutter, L. Pintelon W. Decré, \\ W. Van Bockhaven, W. Coreynen, \\ M. De Looze, G. Van Hootegem
}

\begin{abstract}
The manufacturing industry is increasingly regarded as an essential ingredient of an ecosystem of production of goods and services. Key enabling technologies are considered to be the motors behind the ongoing digital transformation of industry. Given that there are still a number of open questions that need to be addressed in order to develop successful strategies for further implementation of these technologies, and to understand how workplace innovation plays a role in the digital transformation of industry, this paper seeks to design a comprehensive research approach and explains how this approach is applied in the PARADIGMS 4.0 research project on the digital transformation of industry in the region of Flanders, Belgium. Based on the identification of current knowledge gaps, research questions are defined on the topics of technology and work organisation, skills and participation, organisational and regional strategies, and labour market impact. A multi-level, multidisciplinary, multi-method and multi-stakeholder research design was developed in order to study these topics in an integrated way. While this innovative comprehensiveness is seen as a major strength, it is acknowledged that the research design comes with certain risks that need to be tackled.
\end{abstract}

Keywords: Industry 4.0, work organisation, regional strategy, skills, worker participation, job market

\section{Acknowledgements}

This research is supported by grant S006018N of the Research Foundation Flanders (FWO). 


\section{Introduction}

The fourth industrial revolution is characterised by a blurring of distinctions between physical, digital, and biological spheres, as major technological advances are having a profound impact on economies, businesses, and the personal lives of people throughout the world (Schwab 2018). Some of the technological forces in this transition include the development of big data, algorithmic management, 3D printing, quantum computing, smart robots, artificial intelligence, the internet of things, nanotechnology, biotechnology and alternative forms of energy technology (O'Reilly, Ranft, and Neufeind 2018). These key enabling technologies are regarded as the motors behind the ongoing digital transformation of industry.

In Europe, a growing awareness can be noticed that the manufacturing industry is an essential pillar for job growth and prosperity. Strengthening Europe's industrial base and getting manufacturing industry back to Europe has been a key topic for both business and government in recent years. Faced with strong competition from emerging economies, combined with massive outsourcing and offshoring of industrial activity during the 1990s and early 2000s, recent policy and business initiatives have been launched to 'reshore' and 'inshore' activities that were previously offshored. The 'strong industrial base' argument in essence holds that the manufacturing industry itself is important, in the EU responsible for 30 million jobs directly, and twice as many indirectly, $80 \%$ of total EU export and $80 \%$ of private R\&D expenditure (European Commission 2014), but it also forms a strong basis for the service economy (Vendrell-Herrero and Wilson 2017) and as such makes higher contributions to the economy than would be expected based on its size, i.e. its production value and (declining) employment.

Also in the region of Flanders (Belgium), manufacturing industries are considered essential for employment in services, as was stated in a recent position paper from the Class of Technical Sciences of the Royal Flemish Academy of Belgium for Sciences and the Arts (Van Brussel et al. 2016). The manufacturing industry is increasingly regarded as an essential ingredient of an ecosystem of production of goods and services. The, perhaps most important, reason behind the manufacturing renaissance is the introduction and application of the said key enabling technologies. Based on a series of consultations and a stakeholder conference in 2016, the Flemish Government made a concept note (EWI 2017), in implementation of its long-term strategy 'Vision 2050' (Vlaamse Overheid 2015), which stressed the urgent need for coordinated action and the development of a long term vision on Industry 4.0. In support of 'Vision 2050', a report (Sels, Vansteenkiste, and Knipprath 2017) on labour market forecasts was published, with an important section on technology, jobs and 21 st century skills. These documents show the high relevance of the Industry 4.0 related challenges in Flanders. However, there are still a number of open questions with regard to Industry 4.0 that will need to be addressed in order to develop successful strategies for further implementation. In this respect, Howald et al. (2017) propose that workplace innovation should be given a more central place in the process of digitalisation, emphasising the close relationship between organisational performance (labour productivity, innovation capabilities) and better jobs (competence development, wellbeing at work). The authors state that the concept of workplace innovation covers the main elements of a human related perspective for developing work in a digitalised world that aims for comprehensive utilisation of the potentials of human labour as a condition for ensuring innovative ability. Deuse et al. (2011) emphasize that the success of the proclaimed fourth industrial revolution depends crucially on whether it is sustainably anchored in the organisation and implemented in a targeted way. Accordingly, human and technological aspects should be adapted to and aligned with the organisation's structures and processes.

The Paradigms 4.0 research consortium (Dhondt et al. 2018) took up the gauntlet and received funding from the regional Research Foundation - Flanders (FWO) for designing and implementing an extensive study on the digital transformation of industry.

This paper consists of six parts of which this introduction was the first. Based on the identification of current knowledge gaps in the second part, we will define scientific objectives and the related research 
questions in the third part. The fourth part describes the requirements for the research design, which is presented in the fifth part, after which we will further discuss this research design in the sixth part.

\section{State of the Art}

Industry 4.0 builds on the state-of-the-art research which acknowledges that Industry 4.0 technologies will have a deep and disruptive impact on society. However, there is an increasing number of contradicting studies about the exact impact, especially with regards to quality of working life, organisational performance and employment relationships. It is yet unclear how Industry 4.0 technology could foster societal aims, while at the same time cradle high performance organisations.

\subsection{Technology and the labour market}

Fast technological developments generate opportunities and threats for manufacturing industries to innovate. Industry 4.0 technologies are considered to be disruptive for labour markets and organisations (Brynjolfsson and McAfee 2015; Frey and Osborne 2013). This 'disruption' perspective is still the standard way of thinking about the effects of technological change on labour markets (Pfeiffer 2016). However, within this perspective, the expectations about the technological developments tend to be overly optimistic as far as the possible applications of new technologies is concerned. At the same time, expectations with regard to the direct, linear impact of technological developments on labour markets could be labelled as overly pessimistic. Kurzweil's Singularity point is still far away, and Moravec's paradox stating that 'tasks that are trivial for men are difficult for robots and vice versa' is likely to remain valid for a long time (Van Brussel et al. 2016). It must be clear that the panic messages in the popular media about 'the invasion of the robots' and its impact on employment and on the potential and limitations of the emerging technologies are often exaggerated and deserve some reservation. But the 'disruption' perspective also leads to misdirected actions in policy agendas such as employers demanding an immediate change of the educational system. A 'high road' smart industrial specialisation strategy (as explained in the next section) does not only rely on technology, but also on the availability of the appropriate skills in the labour market and in the companies. The model of Frey and Osborne (2013) predicted that about 47 percent of total US employment is at high risk for full digitisation. A Belgian replication study estimated 39 percent at risk (HRW 2016). However, this model assumes that whole occupations rather than specific tasks are being replaced by technology. Arntz et al. (2016) argue that this approach leads to an overestimation of technology impacts, as even high-risk occupations often still contain a substantial share of tasks that are hard to digitize. Their analysis accounts for the heterogeneity of workers' tasks within occupations and leads to loss of $9 \%$ of total employment due to technology across 21 OECD countries. Huang and Rust (2018) argue that Artificial Intelligence job replacement occurs fundamentally at the task level, rather than the job level. It seems that digitisation is unlikely to destroy large numbers of jobs, although it is found to lead to less opportunity for low-qualified workers. More precise concepts and statistics are needed in order to assess the labour market impact of Industry 4.0 technologies.

\subsection{Strategies within entrepreneurial ecosystems}

Industry 4.0 is often part of 'smart specialisation' strategies which regions and countries develop in order to help restructure their economies. Smart specialisation is an innovative approach, promoted by the European Union, that aims to boost growth and jobs, by enabling each region to identify and develop its own competitive advantages (hence 'specialisation'). The term 'smart' in smart specialisation points at the intricate process of 'entrepreneurial discovery' through which regions seek to specialize (Foray 2016). Specifically, with regard to Industry 4.0, we use the term Smart Industrial Specialisation (SIS). Based on a comparative analysis of five West-European countries who were able 
to increase their industrial production capacity between 2001 and 2011, Tshidimba and Costers (2015) identified to two contrasting paths: The Netherlands and Ireland followed a strategy which was largely based on lowering costs (in terms of labour costs, taxes, commodity prices), while Germany, Austria and Sweden based their strategy on their ability to differentiate in order to stay competitive. These countries specialize by investing more in innovation, compared to other countries, and by focusing research and development activities on the industrial sector. This distinction matches the low and high road to industrialisation, where the low road is based on cheap labour, and the high road stresses innovation (Sengenberger, Loveman, and Piore 1990). The promise of a high road strategy is lower unemployment and better, higher paid jobs. In the scientific debate about such strategies, the role of 'ecosystems' is often stressed, which are defined as the strategic interplay of academia, industry and government. The concept of 'entrepreneurial innovation ecosystems' gradually replaces prior thinking about ecosystems, which was strongly focussed on the transfer from knowledge partners towards companies. In an entrepreneurial innovation ecosystem approach, an interdependent set of actors is governed in such a way that it enables entrepreneurial action. This approach may speak directly to practitioners, but its causal depth and evidence base is still rather limited (Stam 2015). The theoretical foundation for such entrepreneurial innovation ecosystems requires more in-depth investigation.

\subsection{Design space in new technology}

The relationship between operator and robot has changed drastically over the years. The type of current human-robot interaction can be categorized as supportive, collaborative, or cooperative (Siciliano and Khatib 2016), ranging from no (intended) physical contact to continuous interaction. The comprehensive digitisation and integration of production and planning along the value chain will also change work organisation, yet forecasts are contradictory. The, for human workers, pessimistic perspective predicts more employee surveillance, more standardized and short-cycle work, poorer quality of working life, and worse working conditions. The key question is to what extent the integration of production data along the value chain will imply a centralisation of control and planning, and hence a decrease of autonomy at the level of working units (Lall et al. 2016). The optimistic perspective emphasizes the opportunities of digital technologies (such as decentralized programming facilities and augmented reality) and robotization (such as exoskeletons and collaborative robots) to enable innovative work organisation models based on teamwork, and to empower operators with decentralized planning, control and fine-tuning (Ittermann, Niehaus, and Hirsch-Kreinse 2015). In current applications and research, the role of the human operator is often defined from the perspective of technological optimisation processes. This implies that tasks of human operators (and teams) are guided by software which is pre-programmed by system developers. The new generation of robots and Cognitive Operator Support Systems (COSS) require optimisation processes where the constraints are more complex: with greater geometrical uncertainties, with a larger task variability, and with more interaction between the operator and the machine (Reardon et al. 2015). As a result of this increased complexity of constraints and optimisation processes, the awareness is rising that pre-programmed software to guide tasks is no longer possible and that software needs to enable operators to define or modify the constraints (Pan et al. 2010). The question remains how and to what extent robots and work processes can jointly be designed in such a way that operators, as part of autonomous teams, have adequate decision authority.

\subsection{Robots, humans and safety}

High technology systems hold the lure of preventing all accidents from happening and creating inherent safe work situations (Parmiggiani et al. 2014). Next to the mechanical autonomy, new robotic systems operate with different sensor systems, actuators and learning systems that help the system identify its environment and act upon it. This approach leads, however, to complicated design choices: how much energy should be diverted to securing a safe working environment, for instance to avoid collision with operators? Such design choices impact the performance of the robot. A 'risk-free' robot 
will probably not be able to deal with heavy loads, or to operate at the high speed that is needed for high productivity. Interestingly, the design choices which are usually made in practice, are mainly technology-driven: actual solutions typically do not include a role for the operator, because of the availability of technological safety options. Such safety approaches which, by design, do not allow the operator to make safety decisions, may be hard to integrate in 'high road' Industry 4.0 applications. The question is which safety approach could lead to inherent safe working conditions, by not only relying on technology. Is a new, more operator-centred approach to robotic systems possible, based on broader occupational safety and health (OS\&H) approaches, such as traditional safety management (focused on accident prevention), Reason's Swiss Cheese Model (1997), and new approaches such as systems thinking (Leveson 2011) and the Zero Accident Vision, which requires participation by all people engaged in the organisation (Zwetsloot et al. 2017)?

\subsection{The skills debate}

Pfeiffer (2016) argues that the main weakness of many studies, such as the one by Frey and Osbourne (2013), is the distinction between routine and non-routine tasks. She proposes an index based on 'labouring capacity' to describe digitisation-resistant components of human work, which is understood as a multidimensional interplay of complex challenges in specific situations, together with the action dimensions that are necessary for adequately responding to these challenges. However, the skills debate is currently mainly focused on the distinction between task- or occupation-based approaches (see Section 2.1) for assessing technology impacts on labour markets and skills. Progress is stalling because a thorough analysis of the connection between both approaches is still missing. On top of this discussion, the European Commission and the employers' associations (e.g. European Commission 2016) are now insisting on the development of 'T-shaped skills', which combine deep skills in a specialized area (the vertical axis of the T) with broad competences for collaboration across disciplines (the horizontal axis of the T). It is obvious that the vertical, occupation-related skills are a primary condition for success in many occupations, and that generic, horizontal skills cannot compensate for the lack of occupation-specific competencies. However, indications are that, on average, Industry 4.0 requires employees with a higher educational level than before. Another issue connected to the discussion on T-shaped skills, is that the changing skill needs also require company policies to adapt, in order to enable employees to expand their skillset during their working career. Dhondt and van Hootegem (2015) argue that team-based environments are needed in order to integrate a great number of individuals with overlapping high-tech skill profiles (Dhondt \& Van Hootegem, 2015). Fragmenting work across many different, specialized tasks hampers the development of T-shaped organisations (Wladawsky-Berger 2015). In short, there is abundant room for further progress in determining the relation between Industry 4.0 technological developments, employee skills and organisation design.

\subsection{Worker participation in Industry 4.0}

Implementing Industry4.0 technologies is likely to have a deep impact on the role of workers within a company and within work processes, on the way they are able to participate in the design and execution of labour processes, and even forms of participation at the company level may change. It is yet unclear what potential opportunities, drivers, hindrances and benefits could be of different forms of worker participation in deep transformations such as projected in the Industry 4.0 visions. How can worker participation become a cornerstone in the shaping of technology, labour processes and workplaces, in order to foster beneficial outcomes for society as a whole, and for workers in particular? Three forms of participation can be distinguished. (1) Direct participation in the work processes relates to the concept of 'employee innovative behavior', when employees actively think about how to change, optimize and innovate the work and business performance (De Spiegelaere, Van Gyes, and Van Hootegem 2014). This connects to the entrepreneurial ecosystems approach (see Section 2.2) as well as to the skills of workers and work organisation design (see Section 2.5). (2) 
Organisational-level decision latitude is defined as shop-floor consultancy on process improvements, division of labour, targets, etc. (Dhondt, Pot, and Kraan 2014). The High Performance Work Systems perspective argues that both innovative employee behaviour and organisation-level decision latitude depend on organisational structures that provide employees with the abilities, motivation and opportunities for such behaviour (Appelbaum et al. 2000). While the determinants of the abilities and motivations are usually dependent on job characteristics, the opportunities are more likely to be dependent on organisational level variables (Oeij et al. 2015). (3) Representative participation refers to participation by elected worker representatives. Representative participation can influence innovation outcomes both positively and negatively, for example when union bargaining simultaneously leads to lower Research and Development expenditure, due to higher wages, and to stronger innovative capacity, due to higher employee trust and group level dynamics, as well as to employee support for the introduction of new forms of work organisation induced by Industry 4.0 and for investment in training (Van den Berg, Grift, and Van Witteloostuijn 2011). Overall, there is a lack of scientific clarity on the precise relation between direct and representative employee participation, job characteristics and innovative employee behavior. A more rigorous specification of the - likely indirect - pathways through which employee participation influences innovation outcomes was explored by Hermans and Ramioul (2015). However, to date, these pathways lack empirical testing.

\subsection{Integration}

Industry 4.0 technology is an important trigger for disrupting changes, but from the overview of a number of important Industry 4.0 building blocks in the previous sections, it must be clear that there are several mediating variables. On top of the indicated research gaps, a yet unanswered question is how to combine and integrate these different building blocks in order to enable a 'high road' digital transformation of industry.

\section{Research Questions}

Based on the overview in the previous part of this paper, we identified four research objectives which were translated into seven research questions. In the next part we will describe the requirements for a research design which allows to study these research questions, in order to realize the four objectives.

\subsection{Technology and work organisation}

The first objective (O1) is to improve scientific knowledge on the relation between Industry 4.0 technologies and the organisation of work. Two research questions were formulated.

RQ1 - Which human-technology interfaces foster optimized quality of working life and increased performance?

RQ2 - What occupational health and safety approaches contribute to digitized workplaces that generate safe, productive and healthy jobs?

\subsection{Technology, skills and participation}

The second objective $(\mathrm{O} 2)$ is to improve scientific knowledge on skills and participation as key dimensions of the employment relationship in Industry 4.0 work environments. Two research questions were formulated. 
RQ3 - What skills are required for Industry 4.0 manufacturing environments?

RQ4 - What social partnerships may enable forms of participation which contribute to technological innovations that foster synergies between quality of working life and organisational performance?

\subsection{Organisational and regional strategies}

The third objective (SO3) is to develop a comprehensive conceptual framework of factors supporting quality of working life and organisational performance in Industry 4.0 work environments, by integrating the separate building blocks, thus laying foundations for organisational and regional high road strategies towards Smart Industrial Specialisation. Two research questions were formulated.

RQ5 What is the combined impact of technology, work organisation, skills, and participation, on quality of working life and organisational performance?

RQ6 What organisational and regional strategies contribute to the development of 'high road' Industry 4.0 manufacturing environments?

\subsection{Labour market impact}

The fourth objective (SO4) is to develop innovative methods for measuring the labour market impact of technological innovations. One research question was formulated.

$R Q 7$ What is the labour market impact of technological innovations in terms of organisations, occupations, and tasks?

\section{Requirements for the research design}

While the previous part consisted of the formulation of research objectives and research questions, we now formulate four requirements for a research design which would allow to study these research questions and explain how these requirements were met. Firstly, the research design needs to encompass multiple levels, from individual jobs to innovation ecosystems, and it should enable an analysis of the linkage between these levels. Secondly, due to the variety of aspects covered by the research questions, a carefully selected group of academic disciplines needs to be involved in the design of the research, as well as in the further empirical and analytical work. Thirdly, because of the differences in level of analysis and disciplinary focus between the seven research questions, the research design should allow separate sets of methods to be used for each research question. Fourthly, the (potential) fields of application of Industry 4.0 technologies encompass a multitude of stakeholders. The research design therefore needs to cover the involvement of a network of motivated stakeholders. In short, a multi-level, multi-disciplinary, multi-method and multi-stakeholder research design is needed.

\subsection{Multilevel}

Table 1 presents an overview of the main topics per research question (RQ) and the respective level(s) of analysis. Industry 4.0 is studied from the micro level of workers and human-technology interfaces, over the meso level of teams and organisations, to the macro level of ecosystems and labour markets. 
Most of the research questions focus on more than one level (including the interconnection between them). Especially RQ5 explicitly focusses on a cross-level integration of Industry 4.0 building blocks in terms of quality of working life (micro) and organisational performance (meso), and RQ6 builds further on the RQ5 insights in order to develop organisational (meso) and regional (macro) strategies.

Table 1 Overview of the main topics per research question and the respective level(s) of analysis.

\begin{tabular}{|l|l|l|}
\hline RQ & Main topics & Level(s) of analysis \\
\hline 1 & Human-technology interfaces & Micro \\
\hline 2 & Occupational health and safety approaches & Micro - Meso \\
\hline 3 & Skills & Micro - Meso - Macro \\
\hline 4 & Participation & Micro - Meso \\
\hline 5 & $\begin{array}{l}\text { Combined impact on quality of working life and organisational } \\
\text { performance }\end{array}$ & Micro - Meso \\
\hline 6 & Organisational and regional strategies & Meso - Macro \\
\hline 7 & Labour market impact & Macro \\
\hline
\end{tabular}

\subsection{Multidisciplinary}

The research questions ask for an interdisciplinary approach and close collaboration between engineers and social scientists. The research team therefore includes mechanical engineers, experts in robotics and safety at work, and social scientists specialized in work organisation, job design, quality of working life, occupational health and safety, worker participation, and business and regional strategies Each research question will be studied by a tailored combination of researchers from different disciplines.

\subsection{Multi-method}

Mixed methods research is usually defined as the use of quantitative and qualitative methods in a single study or series of studies. Although the research design that is presented in Section 5 involves the use of quantitative and qualitative methods, we prefer to use the term multi-method (Dessers et al. 2014). While the term mixed method primarily stresses the connection and combination of several different types of data collection to answer a specific research question, multi-method here refers mainly to the fact that each of the seven research questions will demand specific methods. The research questions refer to different levels of analysis, and their disciplinary focus differs as well. For that reason, no one-size-fits-all method could cover all seven research questions. It is expected to be more effective to choose the right tool for the job at hand. As will be explained in Part 5, the most appropriate and feasible research methods are applied for answering the different research questions, including conceptual studies, descriptive case studies, feasibility studies, impact studies, surveys, focus groups, Delphi studies and desk research. 


\subsection{Multi-stakeholder}

Politicians and industrial sector representatives have clearly expressed the need for Industry 4.0 strategies in the light of the digital transformation of industry (EWI 2017). Although studying the research questions primarily requires a fundamental research approach, eventually the acquired insights and knowledge should evidently enable strategic improvements in practice. Active efforts are taken to achieve the effective transfer, the exploitation and the utilisation of the research results. This research was therefore developed through an intensive preparatory process, which resulted in a strong network of motivated stakeholders (Dhondt et al. 2018). We included a total of 16 valorisation partners in the research who confirmed their participation by a letter of intent. These partners come from following stakeholder groups: companies in the manufacturing industry (count: 6); social partners (4); knowledge and education organisations (3); and policy and support institutions and networks (3). All of them have evidently agreed to be part of the project board, to give support to the implementation of the research, to evaluate research results and, even more important, to support the valorisation of the research results. A valorisation trajectory will run parallel to the execution of the research. This approach is based on the concept of 'concurrent engineering', and implies that fundamental research, valorisation and application of the research results are not considered to be sequential phases. Instead, a series of research-valorisation-application-loops will be organized throughout the research project runtime, based on het future search methodology (Weisbord 1992), which is a meeting technique that helps people to use their capability for action.

\section{Research Design}

Now that the requirements are dealt with, we will present the actual research design. A multi-method approach was developed in order (1) to prepare the studies and to integrate existing information into concepts and frameworks by using conceptual studies, by means of literature review, desk research, and expert discussions; (2) to collect in-depth insights about technological applications, by means of descriptive analyses of workplaces, feasibility studies to test new ideas, and impact studies to analyse results of new designs; (3) to understand strategies of actors in workplaces and organisations by means of focus groups, Delphi studies, and desk research; (4) to identify and understand strategies of stakeholders groups with regard to the labour market, by means of stakeholder meetings, focus groups and Delphi studies; and (5) to create external validity of the collected data, by means of surveys and multi-variate statistics.

In our research design, the in-depth study of Industry 4.0 technologies and the related human-machine interactions take a central place, which enables us to identify alternative human-technology interfaces and organisational designs, and to study their impact on quality of working life, required skills, organisational performance, and possible health and safety risks for workers. Investigating the relationship between technology and work organisation helps to understand the malleability of technology from the perspective of quality of working life and organisational performance. A set of eight case studies covering typical Industry 4.0 technology applications will produce basic data for the joint study of multiple research questions. We selected four types of Industry 4.0 technologies and strive to study two cases of each type. (1) Autonomous robots, which evidently do not require humanmachine interaction during operation, yet they do require maintenance, logistical and supportive activities; (2) Interactive robots, often referred to as collaborative robots or 'cobots'; (3) Wearables, including exoskeletons. The development of these systems has just started. We hope to identify cases where wearables are used in a production environment, and if not, we plan to study wearables in an experimental lab setting; (4) Cognitive Operator Support Systems, which help operators in conducting their activities. Such systems are now starting to get implemented.

Studying cases of these four industrial applications of Industry 4.0 technologies will allow to generate information about the malleability of these technologies in terms of improved quality of working life and organisational performance (RQ1); about the possibilities for healthier and safer work 
environments (RQ2); about the required skills for working in these settings (RQ3); and about pathways for adequate participation (RQ4).

We apply a case study-based design in order to obtain indications on how technology and work organisation related decisions are made in real-life situations. This requires case studies of companies in which technology is being (re)developed; in which decisions concerning implementation are made; in which data can be gathered on desired changes from everyone involved in the production process; in which the feasibility of these desired changes can be investigated; and in which the impact of alternative production set-ups can be measured. Two types of case studies will be needed: (1) Impact studies, which should allow us to better understand which technological and organisational choices were made, and what the possible impacts are of the current set-ups for quality of working life and organisational performance; (2) Feasibility studies in real-life settings and/or design experiments in a lab environment, to explore the possibilities for granting discretionary power to human operators and their teams, for changing and controlling technology applications. These studies should help us understand to what extent and how it could be feasible to adapt technological and organisational dimensions in such a way that quality of working life and organisational performance is fostered.

Both within-case and cross-case analyses will be performed. In combination with literature reviews will these cases provide the building blocks for an integrated scientific approach of the relationship in Industry 4.0 working environments between technology, work organisation, skills and participation on the one hand, and quality of working life and organisational performance on the other hand (RQ5). In a final step, these results will be linked to possible organisational and regional smart specialisation strategies (RQ6). Industry 4.0 stakeholders will be involved to explore the content, validity, and possible deployment of different strategies.

The relationship between technology and the labour market is given a separate place in the research design (RQ7). A literature review will produce a detailed state-of-the-art, which forms the starting point for exploring the conceptual and methodological challenges. We plan to apply the approach developed by Akçomak et al. (2011) to Flemish survey data, and in cooperation with Flemish research and governmental institutes, which will be deploying labour market surveys during the research period, we aim to investigate the possibility to include our new approach in these surveys.

A more detailed overview of the different tasks that will be performed for studying each of the research questions, and of the main methods that will be used, is given in Table 2. 
Table 2. Overview of research objectives, research questions, tasks and main methods

\begin{tabular}{|c|c|}
\hline RO RQ Task & Method \\
\hline \multicolumn{2}{|l|}{ RO1 - Technology and Work Organisation } \\
\hline \multicolumn{2}{|l|}{$\begin{array}{l}\text { RQ1 - Which human-technology interfaces foster optimized quality of working life } \\
\text { and increased performance? }\end{array}$} \\
\hline \multirow[t]{2}{*}{$\begin{array}{l}\text { Study of alternative technological design options in human-machine } \\
\text { interaction that optimize job quality and performance for operators and teams }\end{array}$} & $\begin{array}{l}\text { Literature } \\
\text { review }\end{array}$ \\
\hline & Case study \\
\hline $\begin{array}{l}\text { Evaluation and impact study of the opportunities of the alternative } \\
\text { technological design options for autonomy, learning and cooperation of } \\
\text { operators and teams }\end{array}$ & $\begin{array}{l}\text { Case study } \\
\text { Focus group }\end{array}$ \\
\hline \multirow[t]{2}{*}{$\begin{array}{l}\text { Design of human-machine interface templates and definition of conditions } \\
\text { for implementation }\end{array}$} & $\begin{array}{l}\text { Conceptual } \\
\text { study }\end{array}$ \\
\hline & Design \\
\hline \multicolumn{2}{|l|}{$\begin{array}{l}\text { RQ2 - What occupational health and safety approaches contribute to digitized } \\
\text { workplaces that generate safe, productive and healthy jobs? }\end{array}$} \\
\hline \multirow[t]{3}{*}{$\begin{array}{l}\text { Analysis of Industry } 4.0 \text { job characteristics and assessment of Occupational } \\
\text { Safety \& Health implications }\end{array}$} & $\begin{array}{l}\text { Desk } \\
\text { research }\end{array}$ \\
\hline & Interview \\
\hline & Case study \\
\hline $\begin{array}{l}\text { Development and testing of an adapted Occupational Safety \& Health } \\
\text { approach for Industry } 4.0\end{array}$ & $\begin{array}{l}\text { Design } \\
\text { Case study }\end{array}$ \\
\hline \multicolumn{2}{|l|}{ RO2 - Technology, skills and participation } \\
\hline \multicolumn{2}{|l|}{ RQ3 - What skills are required for Industry 4.0 manufacturing environments? } \\
\hline \multirow[t]{3}{*}{ Assessment of the skills debate } & $\begin{array}{l}\text { Conceptual } \\
\text { study }\end{array}$ \\
\hline & $\begin{array}{l}\text { Desk } \\
\text { research }\end{array}$ \\
\hline & $\begin{array}{l}\text { Literature } \\
\text { review }\end{array}$ \\
\hline \multirow[t]{3}{*}{ Analysis of T-shaped skills structures in the cases } & Case study \\
\hline & Design \\
\hline & Focus group \\
\hline Assessment of T-shaped skills structures in other high-tech environments & Case study \\
\hline \multirow[t]{2}{*}{ Integration of skills structures at team and organisation level } & $\begin{array}{l}\text { Literature } \\
\text { review }\end{array}$ \\
\hline & Case study \\
\hline Connection of micro and meso to macro: the supporting skills ecosystem & Indicator \\
\hline
\end{tabular}




\begin{tabular}{|c|c|}
\hline & $\begin{array}{l}\text { development } \\
\text { Statistics } \\
\text { Focus group }\end{array}$ \\
\hline $\begin{array}{l}\text { RQ4 - What social partnerships may enable forms of participation which } \\
\text { contribute to technological innovations that foster synergies between quality of } \\
\text { working life and organisational performance? }\end{array}$ & \\
\hline Theoretical integration and development of conceptual model & $\begin{array}{l}\text { Literature } \\
\text { review } \\
\text { Conceptual } \\
\text { study }\end{array}$ \\
\hline Test of conceptual model in organisations & $\begin{array}{l}\text { Case study } \\
\text { Interview }\end{array}$ \\
\hline Analysis of forms of participation in innovation in organisations & Survey \\
\hline $\begin{array}{l}\text { Assessment of the feasibility of, and requirements for, new social } \\
\text { partnerships in Industry } 4.0\end{array}$ & Delphi study \\
\hline SO3 - Organisational and regional strategies & \\
\hline $\begin{array}{l}\text { RQ5 - What is the combined impact of technology, work organisation, skills, and } \\
\text { participation, on quality of working life and organisational performance? }\end{array}$ & \\
\hline Integration of the Industry 4.0 building blocks & $\begin{array}{l}\text { Literature } \\
\text { review } \\
\text { Case studies } \\
\text { Conceptual } \\
\text { study }\end{array}$ \\
\hline $\begin{array}{l}\text { RQ6 - What organisational and regional strategies contribute to the development } \\
\text { of 'high road' Industry } 4.0 \text { manufacturing environments? }\end{array}$ & \\
\hline $\begin{array}{l}\text { Identification of possible 'high road' strategies for Industry } 4.0 \text { based } \\
\text { business models }\end{array}$ & 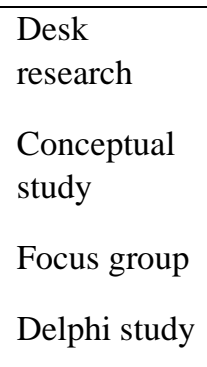 \\
\hline $\begin{array}{l}\text { Identification of organisational capabilities for 'high road' Industry } 4.0 \\
\text { strategies }\end{array}$ & $\begin{array}{l}\text { Case study } \\
\text { Expert panel } \\
\text { Survey }\end{array}$ \\
\hline $\begin{array}{l}\text { Development of a maturity model for interactive robot implementation into } \\
\text { new value creation and capturing strategies }\end{array}$ & $\begin{array}{l}\text { Survey } \\
\text { Desk } \\
\text { research } \\
\text { Content } \\
\text { analysis }\end{array}$ \\
\hline
\end{tabular}




\begin{tabular}{|cl|}
\hline \multicolumn{1}{|c|}{ Identification of ecosystem development opportunities and requirements } & $\begin{array}{l}\text { Conceptual } \\
\text { study } \\
\text { Expert panel }\end{array}$ \\
\hline SO4 - Labor market impact & \\
\hline $\begin{array}{l}\text { RQ7 - What is the labor market impact of technological innovations in terms of } \\
\text { organisations, occupations, and tasks? }\end{array}$ & $\begin{array}{l}\text { Literature } \\
\text { review } \\
\text { Development of a framework for classifying skills, tasks and occupations } \\
\text { Conceptual } \\
\text { study }\end{array}$ \\
\hline Test of the framework & Statistics \\
\hline
\end{tabular}

\section{Discussion}

The research design that is presented in this paper aims to take the multifacetedness of Industry 4.0 developments into account, and involves multiple levels of analysis, multiple disciplines, multiple methods and multiple stakeholders. This innovative comprehensiveness is the major strength of the research design and is in line with current challenges of Industry 4.0 developments, as explained in Part 2 of this paper. However, we acknowledge that this ambitious design comes with certain risks, which need to be addressed. (1) The involvement of multiple research groups carries the risk that a failure to deliver by one of the research groups (for instance, because of staff turnover) might endanger the entire project. We addressed this issue by designing the research in a modular way, in which the research activities which are performed to answer the various research questions, are only loosely coupled. In such a way, a possible problematic execution of a specific research activity is not likely to have much impact on the other research activities. (2) The use of multiple methods at various levels of analysis may risk leading to fragmented results. For that reason, we formulated a separate research question (RQ5) especially for integrating the results from the study of RQ1, RQ2, RQ3, and RQ4, in order to assess the combined impact of technology, work organisation, skills, and participation, on quality of working life and organisational performance. This integration of insights is then further used as input for studying the research question on organisational and regional strategies (RQ6). As indicated, RQ7, on the relationship between technology and the labour market, was given a separate place in the research design. (3) The valorisation of the research results strongly depends on the commitment of the stakeholders and their willingness to use the research results. This important consideration has led us to give our stakeholders more grip on the project and results than usually is the case in similar projects. As we explained, 16 stakeholders are part of the project board and were thus given the power to influence all major decisions and deliverables of the project. A valorisation trajectory will run parallel to the execution of the research, in order to engage a broad group of stakeholders from industry, social partners, knowledge and education organisations, and policy and support institutions, from the very start of the project.

While it cannot be denied that it will be a challenge to bring this ambitious project to a good end, we believe that, by developing a robust and feasible research design, we provided the project with a strong framework for tackling the research questions, and ultimately, for contributing to a 'high road' digital transformation of industry, in Flanders and beyond. This 'high road' will need to be built on workplace innovation thinking. 


\section{References}

Akçomak, I. Semih, Lex Borghans, and Bas ter Weel. 2011. "Measuring and Interpreting Trends in the Division of Labour in the Netherlands." Economist 159 (4): 435-82. doi:10.1007/s10645-011-9168-3.

Appelbaum, Eileen, Thomas Bailey, Peter Berg, and Arne L. Kalleberg. 2000. Manufacturing Advantage. Why High Performance Work Systems Pay Off. Ithaka: Cornell University Press.

Arntz, Melanie, Terry Gregory, and Ulrich Zierahn. 2016. "The Risk of Automation for Jobs in OECD Countries: A Comparative Analysis." OECD Social, Employment and Migration Working Papers 2 (189): 47-54. doi:10.1787/5jlz9h56dvq7-en.

Berg, Annette Van den, Yolanda Grift, and Arjen Van Witteloostuijn. 2011. "Works Councils and Organizational Performance." Journal of Labor Research 32 (2): 136-56. doi:10.1007/s12122011-9105-x.

Brussel, Hendrik Van, Joris De Schutter, Herman Bruyninckx, De Man Hugo, Ludo Gelders, Hubert Van Belle, Bram Vanderborght, Joos Vandewalle, Robert Gobin, and Willy Van Overschée. 2016. "Naar Een Inclusieve Robotsamenleving Robotisering, Automatisering En Werkgelegenheid." KVAB Standpunten, no. 46: 1-53. http://www.kvab.be/en/standpunten/automation-and-robotisation.

Brynjolfsson, Erik, and Andrew McAfee. 2015. The Second Machine Age - Work, Progress, and Prosperity in a Time of Brilliant Technologies. New York - London: W.W.Norton.

Dessers, Ezra, Hubertus J. M. Vrijhoef, Lieven Annemans, Bart Cambré, Steven Dhondt, Johan Hellings, Koen Hermans, et al. 2014. "Towards a Comprehensive Research Design for Studying Integrated Care." International Journal of Care Coordination 17 (3-4): 105-15.

Deuse, Jochen, Kirsten Weisner, André Hengstebeck, and Felix Busch. 2011. "Gestaltung von Produktionssystemen Im Kontext von Industrie 4.0.” In Zukunft Der Arbeit, edited by Erika Zoike, Sven Bungard, Verena Ganske, Franz-Josef Grothaus, Dagmar Hertle, Christian Tewes, Andrea Trümmer, and Karin Kliner, 43-49. Bundesministerium für Wirtschaft und Energie.

Dhondt, Steven, and Geert Van Hootegem. 2015. "Reshaping Workplaces: Workplace Innovation as Designed by Scientists and Practitioners." European Journal of Workplace Innovation 1 (1): 1724.

Dhondt, Steven, Frank Delano Pot, and Karolus O. Kraan. 2014. "The Importance of Organizational Level Decision Latitude for Well-Being and Organizational Commitment." Team Performance Management 20: 307-27. doi:10.1108/TPM-03-2014-0025.

Dhondt, Steven, Monique Ramioul, Ezra Dessers, Joris De Schutter, Liliane Pintelon, Wilm Decr, Paul Matthyssens, Wouter Van Bockhaven, Wim Coreynen, and Geert Van Hootegem. 2018. PARADIGMS 4.0. Building Blocks for a High Road Digital Transformation of Industry. Research and Valorisation Plan. Leuven: Paradigms 4.0.

European Commission. 2014. "Advancing Manufacturing - Advancing Europe. Report of the Task Force on Advanced Manufacturing for Clean Production (EU)." Brussels. https://ec.europa.eu/digital-agenda/en/news/advancing-manufacturing-advancing-europe-reporttask-force-advanced-manufacturing-clean. . 2016. “A New Skills Agenda for Europe.” Brussels.

EWI. 2017. "Startnota Transitie 'De Sprong Maken Naar Industrie 4.0”.," Brussels.

Foray, Dominique. 2016. "On the Policy Space of Smart Specialization Strategies." European Planning Studies 24 (8). Taylor \& Francis: 1428-37. doi:10.1080/09654313.2016.1176126.

Frey, C B, and M A Osborne. 2013. The Future of Employment. How Susceptible Are Jobs to 
Computerization? Oxford: Oxford Martin School.

Hermans, Maarten, and Monique Ramioul. 2015. "Pathways between Representative Employee Participation and Innovation: A Literature Review." In European Academy of Management Conference. Warsaw.

Howaldt, Jürgen, Ralf Kopp, and Jürgen Schultze. 2017. "Why Industrie 4.0 Needs Workplace Innovation - A Critical Essay About the German Debate on Advanced Manufacturing." In Workplace Innovation. Theory, Research and Practice, 45-61. Springer International.

HRW. 2016. "Verslag 2016. Digitale Economie En Arbeidsmarkt.” Brussel.

Huang, Ming Hui, and Roland T. Rust. 2018. “Artificial Intelligence in Service.” Journal of Service Research 21 (2): 155-72. doi:10.1177/1094670517752459.

Ittermann, Peter, Jonathan Niehaus, and Hartmut Hirsch-Kreinse. 2015. Arbeiten in Der Industrie 4.0: Trendbestimmungen Und Arbeitspolitische Handlungsfelder. Düsseldorf: Hans-Böckler-Stiftung.

Lall, Marta Therese, Eva Amdahl Seim, Hans Yngvar Torvatn, and Gaute A. Johansen Knutstad. 2016. "Flow of Information for Autonomous Operators in Industry 4.0 Factories." In $5 \mathrm{~h}$ World Confernce on Production and Operations Management P\&OM Habana 2016 - 05.09.2016 09.09.2016. Havana.

Leveson, Nancy G. 2011. Engineering a Safer World: Systems Thinking Applied to Safety. Vasa. Cambridge, USA: MIT Press. doi:10.1017/CBO9781107415324.004.

O'Reilly, Jacqueline, Florian Ranft, and Max Neufeind. 2018. "Introduction. Identifying the Challenges for Work in the Digital Age." In Work in the Digital Age. Challenges of the Fourth Industrial Revolution, edited by Max Neufeind, Jacqueline O'Reilly, and Florian Ranft, 1-23. London: Rowman \& Littlefield.

Oeij, Peter, Rita Žiauberytė-Jakštienè, Steven Dhondt, Antonio Corral, Peter Totterdill, and Paul Preenen. 2015. Workplace Innovation in European Companies. Dublin: Eurofound. doi:10.2806/543283.

Pan, Zengxi, Joseph Polden, Nathan Larkin, Stephen Van Duin, and John Norrish. 2010. "Recent Progress on Programming Methods for Industrial Robots." Joint 41 st International Symposium on Robotics and 6th German Conference on Robotics 2010, ISR/ROBOTIK 2010 1: 619-26. doi:10.1016/j.rcim.2011.08.004.

Parmiggiani, Alberto, Marco Randazzo, Lorenzo Natale, and Giorgio Metta. 2014. "An Alternative Approach to Robot Safety." IEEE International Conference on Intelligent Robots and Systems, no. Iros: 484-89. doi:10.1109/IROS.2014.6942603.

Pfeiffer, Sabine. 2016. "Robots, Industry 4.0 and Humans, or Why Assembly Work Is More than Routine Work.” Societies 6 (2): 16. doi:10.3390/soc6020016.

Reardon, Christopher, Huan Tan, Balajee Kannan, and Lynn Derose. 2015. "Towards Safe RobotHuman Collaboration Systems Using Human Pose Detection." IEEE Conference on Technologies for Practical Robot Applications, TePRA 2015-Augus: 4-9. doi:10.1109/TePRA.2015.7219658.

Reason, James. 1997. Managing the Risks of Organizational Accidents. London: Routledge.

Schwab, Klaus. 2018. Shaping the Fourth Industrial Revolution. Geneva: World Economic Forum.

Sels, Luc, Sarah Vansteenkiste, and Heidi Knipprath. 2017. Toekomstverkenningen Arbeidsmarkt 2050 (Werk.Rapport 2017 Nr.1). Leuven: Steunpunt Werk, HIVA - KU Leuven.

Sengenberger, W, G W Loveman, and M J Piore, eds. 1990. The Re-Emergence of Small Enterprises: Industrial Restructuring in Industrialized Countries. Geneva: International Institute for Labour 
Studies.

Siciliano, Bruno, and Oussama Khatib, eds. 2016. Springer Handbook of Robotics. Springer International.

Spiegelaere, Stan De, Guy Van Gyes, and Geert Van Hootegem. 2014. "Labour Flexibility and Innovation, Complementary or Concurrent Strategies? A Review of the Literature." Economic and Industrial Democracy 35 (4): 653-66. doi:10.1177/0143831X13492831.

Stam, Erik. 2015. "Entrepreneurial Ecosystems and Regional Policy: A Sympathetic Critique." European Planning Studies 23 (9): 1759-69. doi:10.1080/09654313.2015.1061484.

Tshidimba, Didier, and Nicolas Costers. 2015. "Maak u Klaar Voor de Volgende Industriële Revolutie." Vokawijzer, no. 38: 35.

Vendrell-Herrero, Ferran, and James R. Wilson. 2017. "Servitization for Territorial Competitiveness: Taxonomy and Research Agenda." Competitiveness Review 27 (1): 2-11. doi:10.1108/cr-022016-0005.

Vlaamse Overheid. 2015. "Visie 2050: Een Langetermijnvisie Voor Vlaanderen.” Visie2050. Brussels. doi:10.1017/CBO9781107415324.004.

Weisbord, Marvin Ross. 1992. Discovering Common Ground. San Francisco: Berrett-Koehler Publishers.

Wladawsky-Berger, Irving. 2015. "The Rise of the T-Shaped Organization." http://blog.irvingwb.com/blog/2015/12/the-rise-of-the-t-shaped-organization.html.

Zwetsloot, Gerard I.J.M., Pete Kines, Jean Luc Wybo, Riikka Ruotsala, Linda Drupsteen, and Robert A. Bezemer. 2017. "Zero Accident Vision Based Strategies in Organisations: Innovative Perspectives.” Safety Science 91. Elsevier Ltd: 260-68. doi:10.1016/j.ssci.2016.08.016.

\author{
About the authors \\ Professor Ezra Dessers, KU Leuven, HIVA - Research Institute for Work and Society, Leuven, \\ Belgium. KU Leuven, Centre for Sociological Research, Leuven, Belgium \\ Email: ezra.dessers@soc.kuleuven.be
}

Professor Steven Dhondt, KU Leuven, Centre for Sociological Research, Leuven, Belgium TNO, Leiden, The Netherlands

Professor M Ramioul, KU Leuven, HIVA - Research Institute for Work and Society, Leuven, Belgium

J De Schutter, KU Leuven, Department of Mechanical Engineering, Leuven, Belgium Flanders Make, Core Lab ROB (KU Leuven), Leuven, Belgium

L Pintelon, KU Leuven, Department of Mechanical Engineering, Leuven, Belgium

W. Decré, KU Leuven, Department of Mechanical Engineering, Leuven, Belgium Flanders Make, Core Lab ROB (KU Leuven), Leuven, Belgium

W Van Bockhaven, Antwerp Management School, Antwerp, Belgium

W Coreynen, Antwerp Management School, Antwerp, Belgium Jheronimus Academy of Data Science (JADS), 's-Hertogenbosch, The Netherlands 
M De Looze, TNO, Leiden, The Netherlands, Vrije Universiteit Amsterdam, The Netherlands

G Van Hootegem, KU Leuven, HIVA - Research Institute for Work and Society, Leuven, Belgium, KU Leuven, Centre for Sociological Research, Leuven, Belgium 